\title{
Gastric Cancer Revealed by a Perforated Ulcer: A Case Report and Review
}

\author{
Sètondji G. R. Attolou ${ }^{*}$, Christel M. Laleye1, Djifid M. Seto², Ismaïl Lawani ${ }^{3}$, Dansou G. Gbessi ${ }^{1}$, \\ Delphin K. Mehinto ${ }^{1}$
}

${ }^{1}$ University Clinic for Visceral Surgery, Hubert-Koutoukou-Maga National University Medical Center, Cotonou, Benin

${ }^{2}$ Regional Medical Center of Allada, Allada, Benin

${ }^{3}$ University Hospital Center of Oueme-Plateau, Porto-Novo, Benin

Email: *attolougilles@yahoo.fr

How to cite this paper: Attolou, S.G.R. Laleye, C.M., Seto, D.M., Lawani, I., Gbessi, D.G. and Mehinto, D.K. (2020) Gastric Cancer Revealed by a Perforated Ulcer: A Case Report and Review. Surgical Science, 11, 399-404.

https://doi.org/10.4236/ss.2020.1112042

Received: October 5, 2020

Accepted: December 6, 2020

Published: December 9, 2020

Copyright (c) 2020 by author(s) and Scientific Research Publishing Inc. This work is licensed under the Creative Commons Attribution International License (CC BY 4.0)

http://creativecommons.org/licenses/by/4.0/

\begin{abstract}
Introduction: Gastric cancer is not typically a surgical emergency. However, it can evolve into urgent complications such as a perforation. We report a case of a perforated gastric ulcer that turned out to be a cancer. Observation: A 52-year-old man was admitted to the emergency department of $\mathrm{Hu}-$ bert-Koutoukou-Maga National University Medical Center in Cotonou for generalized abdominal pain. He was diagnosed with acute generalized peritonitis with perforated gastric ulcer, establishing a surgical indication. An antral perforation was found and a simple closure was performed. Anatomopathological examination of the surgical piece revealed a gastric adenocarcinoma within the granulation tissue. Following the impact assessment, he underwent a second surgery where a distal gastrectomy was performed with D2 lymphadenectomy followed by gastrojejunostomy. He developed an anastomotic gastrointestinal fistula during the postoperative period but was successfully medically treated. The patient received adjuvant chemotherapy with Epirubicin, Cisplatin and 5-Fluorouracil. The patient is still alive, 3 years after the gastrectomy. Conclusion: When faced with a perforated gastric ulcer, one must also consider a neoplastic cause. The emergency surgical treatment depends on the general condition of the patient and the pre-existing co-morbidities, the choice being made between a one-stage versus two-stage gastrectomy.
\end{abstract}

\section{Keywords}

Gastric Ulcer, Perforation, Cancer, Simple Closure, Gastrectomy

\section{Introduction}

Gastric cancer (GC) is a common disease [1]. It is the second leading cause of 
cancer-related deaths worldwide [2]. In the majority of cases it is an adenocarcinoma [3] [4] with various forms (vegetating, ulcerated or infiltrative forms). Gastric cancer is not classically a surgical emergency. However, it can evolve into emergency complications such as hematemesis, perforation leading to peritonitis [5]. Gastric cancer presenting with a gastric perforation is a rare event, accounting for less than $1 \%$ of gastric cancer [6]. Its treatment is not consensual [7], some focusing on the management of the peritonitis emergency and others on the technical oncological aspects of surgery. We report a case of a perforated gastric ulcer that turned out to be cancer and compare our treatment with literature.

\section{Observation}

A 52-year-old man consults the emergency department of the Hubert-Koutoukou-Maga National University Medical Center in Cotonou for generalized abdominal pain. The onset dated back to 4 days after a fasting period by a cramp-like epigastric pain. It generalized 24 hours before admission. He also reported a history of undocumented epigastralgia. Clinical examination noted: a poor general condition, a temperature of $375^{\circ} \mathrm{C}$, a normal blood pressure and peritoneal irritation syndrome. Frontal abdomen X-ray showed bilateral pneumoperitoneum. The patient was admitted to the operating room on diagnosis of acute generalized peritonitis by gastric ulcer perforation.

Surgery revealed a punctiform perforation with indurated edges on the anterior surface of the antrum. Simple closure was performed after resection of the edges (Figure 1). Anatomopathological examination concluded to a gastric adenocarcinoma. Extension screening revealed no metastasis. The patient underwent one month later a second surgery and a partial gastrectomy was performed with D2 lymph node excision and Billroth II gastrojejunostomy (Figure 2). Anatomopathological examination of the specimen concluded that the adenocarcinoma was of intestinal type, staged PT3N3MX having infiltrated the gastric wall up to the serosa (Figure 3). Ten lymph nodes were invaded out of the

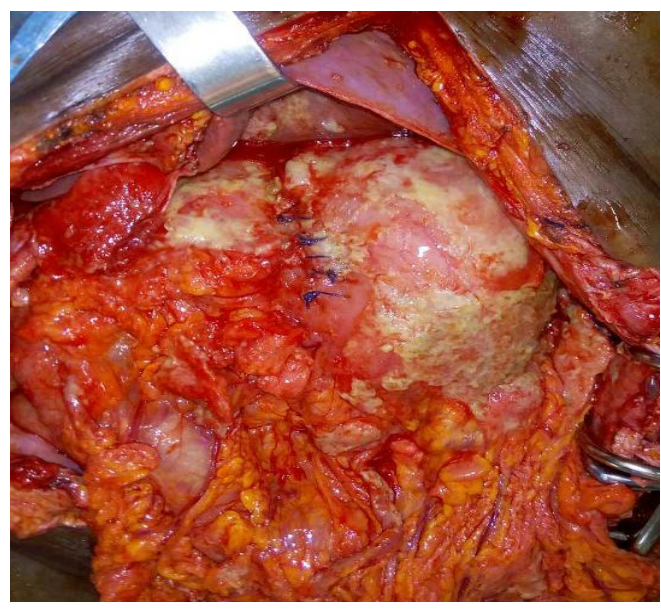

Figure 1. Simple closure performed during first surgical intervention. 


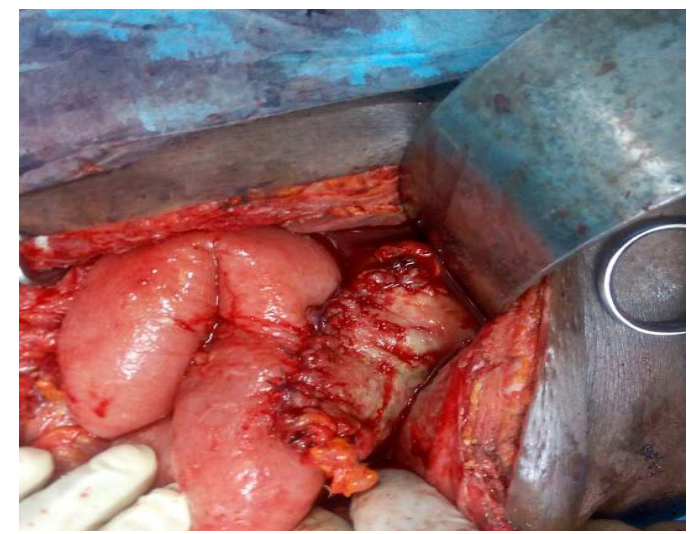

Figure 2. Billroth II gastrojejunostomy performed during second surgical intervention.
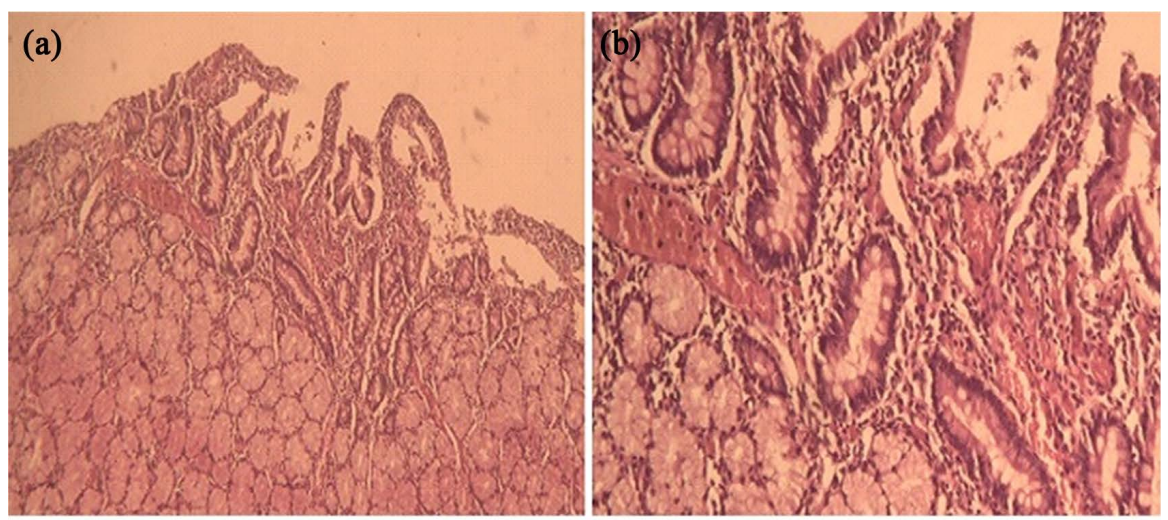

Figure 3. Anatomopathology findings. (a) Histological appearance of the tumor (HE $\times 40$ ) showing a hyperplastic gastric epithelium with adenomatous-like glands in the chorion; (b) Histological aspect of the tumor $(\mathrm{HE} \times 100)$ showing a moderately differentiated tubular adenocarcinoma. The tumor spreads to the serosa.

eighteen lymph nodes found. The proximal and distal surgical section slices were uninvaded. Post-operatively, an anastomotic digestive fistula occurred and was successfully treated medically. The patient received adjuvant chemotherapy with the ECF protocol (Epirubicin, Cisplatin and 5-Fluorouracil). The patient is still alive, 3 years after the gastrectomy.

\section{Discussion}

Gastric cancer (GC) is exceptionally revealed by a perforation. In a study conducted by Franco R et al. [8] on 2564 patients, the incidence rate of perforation among gastric carcinomas was less than $1 \%(0.39 \%)$. In most cases, gastric carcinoma is not suspected to be the cause of perforation prior to emergency laparotomy [8]. According to Lehnert $\mathrm{T}$ et al. [9] the only preoperative argument that could guide the surgeon is the age of the patient. Indeed, the average age of patients presenting a perforated gastric cancer is 65 , whereas patients with perforated benign gastric ulcer are younger around the age of 50 . However, our patient is 52 years old and has a perforated GC. Another one [10] refers to weight loss as a presumptive factor. In fact, there are no strong clinical arguments for 
the diagnosis of cancer in a patient with a perforated gastric ulcer and the main method to confirm malignant perforation is intraoperative frozen section, which also is the primary clinical standard at present [11] [12]. Often, the invasion of the serosa and perigastric lymph nodes indicates stage III or IV TNM classification [13]. However, it is reported in the literature that $20 \%$ to $30 \%$ of cases of perforated gastric cancer are early stage, which makes the situation challenging [8] [13].

The abdominal X-ray aims to confirm perforation and CT scan with contrast injection could show the presence of malignant gastric ulceration (extension of the ulcer to the body of the stomach, localized thickening of the gastric wall, contrast of the lesion, presence of adenopathies or even metastases) but a context of perforation prevents digestive opacification and reduces the sensitivity of this examination [14].

Surgery is undoubtedly the only potentially curative treatment for gastric cancer [1]. However, we need to determine during laparotomy for perforated gastric ulcers, whether the lesion is a cancer or benign ulcer. Unfortunately a therapeutic decision must be taken urgently without the help of extemporaneous examination due to their limited availability in our context. As an expert, Ménégaux F [11], states that considering the antral localization of the tumor, an emergency distal gastrectomy provides a better guarantee of an efficient treatment in case of a cancer. This is confirmed by the study by Adachi Y et al. [13] on perforated gastric cancer, the largest study on this subject $(n=155)$, carried out in Asia. Emergency gastrectomy was performed in 83\% of the cases with 7\% of mortality compared to $70 \%$ in the case of perforation repair. Moreover, gastrectomy is also well adapted to a benign gastric ulcer since it leads to healing with a low long-term recurrence rate compared to local resection and suture [11].

On the other hand, some authors [8] support perforation repair because of the fragile state of these patients who could not withstand major surgery in this emergency. A recent systematic review [7] revealed a mortality of $11.4 \%$ and $1.9 \%$, respectively, in one-stage versus two-stage gastrectomy $(P=0.010)$. According to Wenjun Xiong et al. [12] a long-term survival should be considered and $\mathrm{R} 0$ resection is the most important. When $\mathrm{R} 0$ resection cannot be achieved in the initial treatment phase, palliative gastrectomy should be avoided (Prefer simple perforation repair) [12]. They advocate that advanced GC with acute perforation undergoing initial perforation repair can receive subsequent neoadjuvant therapy. A second stage surgery should depend on the response to therapy [12]. We performed a two-stage gastrectomy but the secondary surgery was delayed (1 month) while performing additional investigations. Normally, it should be performed a few days after the first surgery in order to avoid peritoneal adhesions or peritoneal carcinomatosis [11].

In summary, at present, high-level evidence is absent for surgical treatment and there is no guideline or consensus for diagnosis and treatment. Therefore, it 
is necessary to explore and establish a comprehensive process of diagnosis and surgical treatment for acute perforated GC, which may be very helpful for first-line surgeons and can also improve the short-term outcomes and long-term survival for GC with acute perforation.

\section{Conclusion}

Acute perforation of gastric cancer is few. There is no guideline or consensus for its treatment. We suggest that one step gastrectomy is the treatment of choice in a patient with a good general condition and no underlying pathology and if R0 resection is possible. Otherwise, a simple perforation repair should be performed followed in a second step by a gastrectomy.

\section{Conflicts of Interest}

The authors declare no conflicts of interest regarding the publication of this paper.

\section{References}

[1] Bohanes, P., Roth, A.D., Hube, O., Aapro, M.S. and Plan, P.A. (2009) Cancer gastrique, une prise en charge multidsciplinaire. Revue Médicale Suisse, 5, 1569-1575.

[2] Kamangar, F., Dores, G.M. and Anderson, W.F. (2006) Patterns of Cancer Incidence, Mortality, and Prevalence across Five Continents: Defining Priorities to Reduce Cancer Disparities in Different Geographic Regions of the World. Journal of Clinical Oncology, 24, 2137-2150. https://doi.org/10.1200/JCO.2005.05.2308

[3] Ayite, A.E., Adodo, K., Dosseh, E., Abita, T. and Ocloo, A. (2004) Prise en charge du cancer primitif de l'estomac au CHU de Lomé. A propos de 63 cas. La Tunisie Medicale, 82, 747-752.

[4] Roberto, B., Fazio, N. and Fabrizio, L. (2010) Résultats de la chirurgie après chimiothérapie neoadjuvante a base de docetaxel dans le cancer gastrique localement avancé. World Journal of Gastroenterology, 21, 868-874.

[5] Dembélé, B.T., Togo, A., Kanté, L., Traoré, A., Diakité, I., Tounkara, C.Y., Samaké, B., Keita, M. and Diallo, G. (2012) Cancers gastriques non résécables dans le service de chirurgie générale CHU Gabriel Toure Bamako. Mali Médical, 27, 14-18.

[6] Kasakura, A.J.A., Fujii, M.F. and Takayama, T. (2002) Management of Perforated Gastric Carcinoma: A Report of 16 Cases and Review of World Literature. The American Surgeon, 68, 434-440.

[7] Melloni, M., Bernadi, D., Asti, E. and Bonavina, L. (2020) Perforated Gastric Cancer. A Systematic Review. Journal of Laparoendoscopic \& Advanced Surgical Techniques, 30, 156-162. https://doi.org/10.1089/lap.2019.0507

[8] Franco, R., Simone, R., Daniele, M., Giovanni, D.M., Corrado, P., Paolo, M., Giovanni, C. and Enrico, P. (2006) Perforated Gastric Carcinoma: A Report of 10 Cases and Review of the Literature. World Journal of Surgical Oncology, 4, 19.

[9] Lehnert, T., Buhl, K., Dueck, M., Hinz, U. and Herfarth, C. (2000) Two-Stage Radical Gastrectomy for Perforated Gastric Cancer. European Journal of Surgical Oncology, 26, 780-784. https://doi.org/10.1053/ejso.2000.1003

[10] Pospai, D., Sobhani, I. and Mignon, M. (2000) Maladie ulcéreuse duodénale et gastrique non compliquée. In: Rambaud, J.C., Ed., Traité de Gastro-entérologie, 
Flammarion Médecine-Sciences, Paris, 329-346.

[11] Vibert, E., Boufflerd, C., Regimbeau, J.M. and Menegaux, F. (2005) Ulcère gastrique perforé: Suture ou gastrectomie. Annales de Chirurgie, 130, 92-95. https://doi.org/10.1016/j.anchir.2005.01.006

[12] Xiong, W.J., Wang, W. and Wan, J. (2018) Surgical Strategy of Diagnosis and Treatment for Acute Perforated Gastric Cancer. Chinese Journal of Gastrointestinal Surgery, 21, 1218-1222.

[13] Adachi, Y., Mori, M., Maehara, Y., Matsumata, T., Okudaira, Y. and Sugimachi, K. (1997) Surgical Results of Perforated Gastric Carcinoma: An Analysis of 155 Japanese Patients. The American Journal of Gastroenterology, 92, 516-518.

[14] Stabile Ianora, A.A., Wolowiec, A., Francioso, G., Scardapane, A., Rotondo, A. and Angelelli, G. (2001) Benign and Malignant Gastric Ulcer: CT Findings. La Radiologia Medica, 102, 32-36. 